\title{
VOZ DAS COMUNIDADES: ESTRATÉGIAS DISCURSIVAS SOBRE A VIOLÊNCIA NO COMPLEXO DO ALEMÃO
}

\author{
VOZ DAS COMUNIDADES: DISCURSIVE STRATEGIES ON VIOLENCE IN THE \\ COMPLEXO DO ALEMÃO
}

\section{FRANCISCO LAERTE JUVÊNCIO MAGALHÃES ${ }^{1}$ \\ MARCELA PACHÊCO CHAVES ${ }^{2}$}

\begin{abstract}
RESUMO: O desenvolvimento de tecnologias móveis tem influenciado diversas atividades, e uma delas é o jornalismo. Tal influência tem causado mudanças nas etapas de produção, consumo e distribuição de notícias e propiciado a cidadãos comuns produzir conteúdo, o que antes estava restrito às empresas de comunicação tradicionais. Um exemplo é o Voz das Comunidades, meio de comunicação alternativo produzido por moradores do Complexo do Alemão, no Rio de Janeiro (RJ), que tem como objetivo apresentar outra representação dos fatos relacionados às favelas, diferentemente do que é comumente visto em meios de comunicação tradicionais. Através da Análise de Discurso Crítica (ADC), analisamos que marcas discursivas estão impressas em artigo de opinião do Voz das Comunidades e os discursos produzidos por ele. Com a pesquisa, percebemos que a existência de uma voz local, que tem liberdade de retratar alguns de seus anseios e necessidades, é de significativa importância, entre outas considerações.
\end{abstract}

Palavras-chave: Tecnologias móveis. Jornalismo. Voz das Comunidades. Discurso.

\begin{abstract}
The development of mobile technologies has influenced many activities, and one of them is journalism. Such influence has caused changes in the stages of news production, consumption and distribution and has enabled ordinary citizens to produce content, which was previously restricted to traditional media companies. An example is the Voz das Comunidades, an alternative medium produced by residents of Complexo do Alemão, in Rio de Janeiro (RJ), which aims to present another representation of facts related to slums, unlike what is commonly seen in media traditional communication. Through Critical Discourse Analysis (ADC), we analyze which discursive marks are printed in the opinion article of the $\mathrm{VOz}$ das Comunidades and the discourses produced by it. With the research, we realize that the existence of a local voice, which is free to portray some of its wishes and needs, is of significant importance, among other considerations.
\end{abstract}

Key words: Mobile technologies. Journalism. Voz das Comunidades. Discurse.

\footnotetext{
${ }^{1}$ Doutor em Comunicação pela Escola de Comunicação da Universidade Federal do Rio de Janeiro (ECOUFRJ). Mestre em Comunicação e Cultura pela ECO-UFRJ. Brasil, Piauí, Teresina. E-mail: flaerte@msn.com 2 Mestra em Comunicação pela Universidade Federal do Piauí (UFPI). Brasil, Piauí, Teresina. E-mail: marcelapacheco.c@gmail.com
} 


\section{INTRODUÇÃO}

Um dos elementos mais característicos dos seres humanos é a capacidade de se comunicar, questionar e refletir o mundo ao redor. Por conta disso, a vida em sociedade é atravessada pela comunicação em seus mais variados níveis, que vão de conversas informais, debates, produções jornalísticas, entre outros.

E por falar em jornalismo, tal atividade já vivenciou ao longo do tempo diferentes fases desde o seu surgimento. Resumidamente, algumas delas foram: o período do jornalismo literário, passando pela comunicação de massa, pela consolidação e domínio de grandes empresas sobre o setor e pelo boom da era tecnológica no fim do século XX, que se desenvolve até os dias atuais ${ }^{3}$. Durante essas etapas de transição, mudanças ocorreram em diversas perspectivas. Seja em relação às condições de trabalho, às rotinas produtivas ou aos meios utilizados para produção, consumo e distribuição das produções jornalísticas.

Neste artigo, temos como foco a produção jornalística amparada pelas novas tecnologias móveis que influenciaram não apenas as rotinas dos meios de comunicação, mas também a possibilidade de tal conteúdo ser produzido por outros atores além das empresas tradicionais já existentes. Nesse contexto, destacamos a atividade jornalística realizada por meios de comunicação alternativos, possibilitada e potencializada pelas novas tecnologias, em específico o caso do jornal Voz das Comunidades, a ser analisado nos tópicos posteriores.

Após esta abordagem, realizamos nesta pesquisa a análise discursiva de um dos artigos publicados no respectivo portal, orientados pela Análise de Discurso Crítica (ADC). Segundo Van Dijk ${ }^{4}$, a ADC “em vez de focalizar problemas puramente acadêmicos ou teóricos, toma como pontos de partida problemas sociais vigentes, e assim adota o ponto de vista dos que sofrem mais" (1986, p. 4). Através deste enfoque, buscamos encontrar no artigo de opinião analisado as marcas discursivas que demonstrem que tal discurso é produzido do ponto de vista de um morador da comunidade e ainda que representações estão inseridas neste discurso.

\section{MÍDIA ALTERNATIVA: JORNAL VOZ DAS COMUNIDADES}

O jornal Voz das Comunidades ${ }^{5}$ foi criado no ano de 2005 por um jovem de apenas 11 anos de idade, Rene Silva, estudante de uma escola municipal do bairro Higienópolis, no

\footnotetext{
${ }^{3}$ O VIGILLANTE. As fases do jornalismo. https://ovigillante.wordpress.com/2010/09/08/as-fases-dojornalismo-resumo. (último acesso em 23/112018).

${ }^{4}$ VAN DIJK, Teun. Racism in the press. London: Arnold, 1986.

${ }^{5}$ A história do Voz das Comunidades pode ser lida com mais detalhes no próprio portal. VOZ DAS COMUNIDADES. Nossa história. http://www.vozdascomunidades.com.br/geral/nossa-historia/ (úlitmo acesso em 26/10/2017).
} 
Rio de Janeiro. Com o objetivo de mostrar, através do jornalismo, uma visão das favelas ${ }^{6}$ diferente da representação repassada pelos meios de comunicação tradicionais, Rafael deu origem ao jornal Voz das Comunidades.

O Voz, até então restrito ao contexto do Complexo do Alemão, ganhou destaque nacional no final do ano de 2010 durante a ocupação da comunidade pela Polícia Militar do Rio de Janeiro (PM-RJ), a qual foi transmitida e narrada ao vivo pelos jovens através do Twitter $^{7}$. Os meios de comunicação tradicionais, sem condições de ir até o Complexo, se utilizaram da transmissão do Voz; entre eles, a TV Globo, por exemplo. Tal acontecimento é um reflexo do impacto que as novas tecnologias móveis têm causado nas rotinas de produção do jornalismo. Dessa forma,

O jornalismo móvel se torna imbatível nessas situações de emergência quando as equipes de reportagens tradicionais levam tempo até chegar aos locais com veículos de microondas, satélites e toda a preparação para entradas ao vivo. (SILVA ${ }^{8}, 2009$, p.90).

A partir desse período, o jornal passou a estar presente também na web através do respectivo portal e, atualmente, é composto ${ }^{9}$ por jovens moradores do Completo do Alemão, comunidade em que atua, e tem uma tiragem mensal de 10 mil exemplares ${ }^{10}$ gratuitos. Também tem parceria com meios de outras comunidades, como PavãoPavãozinho e Cantagalo (PPG Informativo), Cidade de Deus (Os Arteiros), Complexo da Penha (Heróis do Complexo), Complexo da Maré (Papo Relíquia), entre outras.

Desde então, o Voz tem abordado diversos temas relacionados ao cotidiano da comunidade. De textos apenas informativos a opinativos, os colaboradores falam

\footnotetext{
${ }^{6}$ Favela é uma "área que combina as seguintes características: acesso inadequado à água potável; acesso inadequado à infraestrutura de saneamento básico e outras instalações; baixa qualidade das unidades residenciais; alta densidade e insegurança quanto ao status da propriedade" (PRETTO; MARZULO. O conceito de favela/slum pelo IBGE e pela https://www.lume.ufrgs.br/bitstream/handle/10183/92016/Poster 30704.pdf?sequence=2>. (último cesso em $26 / 10 / 2017$.

7 "Considera-se o Twitter como uma rede social que permite a troca de informações "de forma descentralizada entre interagentes situados em diversos pontos do ciberespaço, podendo ser utilizado para as mais diversas finalidades, incluindo os usos para filtrar e para comentar notícias" (ZAGO, Gabriela da Silva. Recirculação jornalística no twitter: filtro e comentário de notícias por interagentes como uma forma de potencialização da circulação. 2011. Dissertação - Universidade Federal do Rio Grande do Sul, Porto Alegre, p. 13.

8 SILVA, Firmino Fernando. Repórteres em campo com tecnologias móveis conectadas. In: BARBOSA, Suzana; MIELNICZUK, Luciana. Jornalismo e Tecnologias Móveis. Covilhã: Labcom, 2009. p. 91-112.

${ }^{9}$ VOZ DAS COMUNIDADES. Ficha técnica. http://www.vozdascomunidades.com.br/ficha-tecnica/ (úlitmo acesso em 26/10/2017).

10 EL PAÍS. A voz da comunidade que corre $\quad$ o Rio. http://brasil.elpais.com/brasil/2015/04/05/politica/1428194084 073598.html. (último acesso em 23/11/2017).
} 
sobre cultura, educação, segurança pública, entre outros assuntos que são disponibilizados gratuitamente na web, sem restrições ao conteúdo.

Uma consideração importante que merece ser citada neste ponto da pesquisa refere-se à ampliação da atividade jornalística proporcionada $\mathrm{e}$ potencializada com o desenvolvimento das tecnologias móveis como tablets e smartphones com acesso à internet. Mesmo que tal acesso a esse recurso seja um fator limitador, é inegável a sua popularização, principalmente no Brasil, onde 107,9 milhões ${ }^{11}$ de pessoas maiores de 10 anos de idade fazem uso. Desse modo,

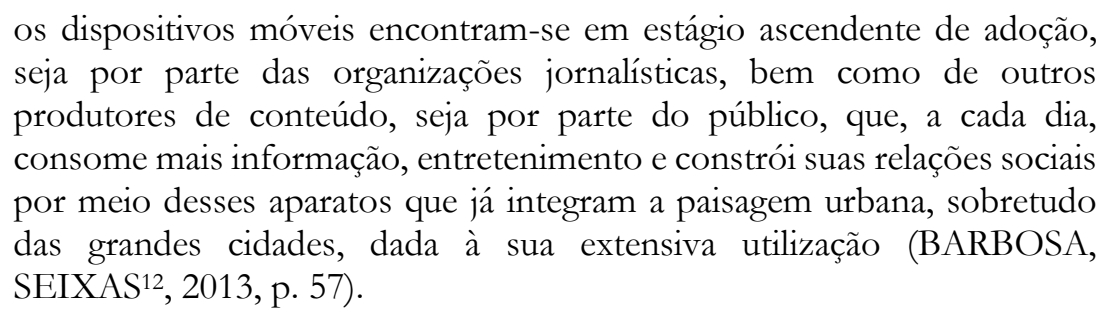

Nesse contexto, têm surgido novos produtores de conteúdo, a exemplo de Rene Silva e sua equipe, e não apenas os meios de comunicação tradicionais. Neste novo momento, os cidadãos comuns têm tido a oportunidade inédita de participarem ativamente dos processos comunicacionais, "vencendo barreiras, ganhando representação, divulgando seus produtos/serviços e sendo ouvidas." (EVANGELISTA ${ }^{13}, 2008$, p.2).

\section{ANÁLISE DO DISCURSO DO VOZ DAS COMUNIDADES}

Após essa abordagem, passamos para a análise discursiva crítica de um artigo retirado do portal do Voz das Comunidades, intitulado de "Opinião: Seis anos de ocupação $^{14}$,, e produzido pelo morador Betinho Casas Novas, de 27 anos, repórter fotográfico e cinematográfico do jornal. No texto, Betinho propõe uma análise sobre os seis anos da presença da PM-RJ no Complexo do Alemão.

\footnotetext{
${ }_{11}$ Dados referentes à pesquisa realizada pela NIC.br, ligada ao Comintê Gestor da Internet no Brasil (CGI.br), em 2017. TELE SÍNTESE. 61\% dos brasileiros têm acesso à Internet. http://www.telesintese.com.br/ticdomicilios-2016/. (último acesso em 29/07/2019).

12 BARBOSA, Suzana; SEIXAS, Lia. Jornalismo e Tecnologias Móveis. In: BARBOSA, Suzana. MIELNICZUK, Luciana (Orgs.). Jornalismo e tecnologias móveis, 2013. Labcom. p. 51 - 74.

13 EVANGELISTA, Ana Paula Souto. Meios de Comunicação Tradicionais X Mídias Alternativas, Como Está a Qualidade da Informação que Chega à População? http://www.intercom.org.br/papers/nacionais/2008/resumos/r3-1448-1.pdf. (último acesso em 22/04/2019).

14 DOZ COMUNIDADES. Seis anos de ocupação. https://www.vozdascomunidades.com.br/comunidades/complexo-do-alemao/opiniao-seis-anos-deocupacao/. (último acesso em 29/07/2019).
} 
Como mencionado anteriormente, utilizamos como aporte teórico-metodológico a ADC, com base nas teorias de Norman Fairclough ${ }^{15}$ (2001) que apresenta um quadro teórico significativo para aplicação em pesquisa científica social. A ADC se caracteriza como "uma abordagem científica interdisciplinar para estudos críticos da linguagem como prática social." (RESENDE, RAMALHO ${ }^{16}$, 2011, p. 12). Assim sendo, tal abordagem do texto se utiliza de categorias textuais de análise para busca dos objetivos descritos. Como explicam Resende e Ramalho (2011), “as categorias linguísticas aplicadas à análise de textos concretos não se justificam em si mesmas, mas no que possibilitam compreender acerca do funcionamento social da linguagem" (p. 21).

Além disso, o estudo sobre discurso está sedimentado sobre outros preceitos básicos. Segundo Norman Fairclough, no livro "Discurso e Mudança Social", conceitua discurso como "o uso da linguagem como forma de prática social e não como atividade puramente individual ou reflexo de variáveis situacionais" (2001, p. 91).

Assim, o conceito do uso da linguagem através do discurso é acompanhado de alguns pressupostos fundamentais. A prática (uso) o revela como uma atividade e o caráter social demonstra a necessidade de existir uma estrutura social que o sustente. Inicialmente, tal sistema estruturado pode ser pré-existente ao discurso, sustentando-o. Mas o discurso pode agir também na interrupção dessa estrutura e no surgimento de outra. Sobre isso, Fairclough considera que

O discurso contribui para a constituição de todas as dimensões da estrutura social que, direta ou indiretamente, o moldam e o restringem: suas próprias normas e convenções, como também relações, identidades e instituições que lhe são subjacentes (FAIRCLOUGH, 2001, p. 91).

Essa transformação que ocorre através do uso da linguagem a nível social pode ser compreendida quando se observa que o discurso atua na modificação de crenças préexistentes a ele. Em especial, a produção de conteúdo do Voz das Comunidades age neste sentido, ao se intitular como "um veículo de comunicação das favelas, para as favelas", o que influencia todo discurso produzido, diferentemente dos grandes maios de comunicação tradicionais. É o que Fairclough (2001) explicita quando afirma que "as práticas discursivas em mudança contribuem para modificar o conhecimento, as relações sociais e as identidades sociais” (p. 27). Entende-se, assim, que o discurso, através do uso articulado da linguagem,

\footnotetext{
${ }^{15}$ FAIRCLOUGH, N. Discurso e mudança social. Brasília: Editora Universidade de Brasília, 2001.

${ }^{16}$ RESENDE, Viviane; RAMALHO, Viviane. Análise de Discurso (para a) Crítica: O texto como Material de Pesquisa. Campinas: Pontes, 2011. v. 1.
} 
resulta na produção de sentidos, sejam eles crenças, informações, representações, entre outros.

Além de entender o significado de discurso associado ao uso da linguagem, também é fundamental compreender as funções que ela desempenha. É o que Fairclough apresenta como as três funções (ou modos de ação) da linguagem. De forma geral, a linguagem atua em forma de gênero, de representação e de estilo.

Ao funcionar como um modo particular de ação, o discurso constitui gêneros discursivos e desempenha a função Acional. O gênero dos textos analisados neste trabalho corresponde ao artigo de opinião publicado no portal do Voz.

Outra função é a de construção de representações de aspectos da vida social. Essa funcionalidade constitui os discursos e é nomeada de Representacional. No artigo de opinião selecionado, essa função volta-se para a representação ou discursos que o colunista constrói no texto sobre os seis anos de ocupação da PM-RJ no Complexo do Alemão, através da Unidade de Polícia Pacificadora (UPP). Sobre a função representacional, Fairclough considera que

\begin{abstract}
os atores sociais, no curso de sua atividade, produzem não só representações das práticas em que estão inseridos, como de outras, e incorporando-as às suas próprias. Além disso, atores sociais irão produzir representações de modo distinto, dependendo da posição que eles ocupam dentro de suas práticas. A representação é um processo de construção social das práticas (FAIRCLOUGH ${ }^{17}, 2005$, p. 309).
\end{abstract}

A terceira função da linguagem corresponde às posições de cada ator social dentro da prática e seu desempenho quanto a ela. Chamada de função Identificacional, corresponde aos tipos de fala individuais, aos estilos. Os estilos percebidos neste trabalho correspondem aos do articulista e morador do Completo do Alemão, Betinho Casas Novas, o que influencia completamente seu discurso e representações produzidas no texto analisado. Sobre a função identificacional, Fairclough (2005) comenta que

Os médicos, professores ou ministros de governo, por exemplo, não têm simplesmente estilos semióticos em razão de sua posição nas práticas. Cada posição é desempenhada com estilos diferentes, dependendo de aspectos de identidade que excedem a construção das diversas posições. Os estilos são maneiras de ser, identidades, em seu aspecto semiótico (FAIRCLOUGH, 2005, p. 310).

É válido considerar que a articulação entre o uso da linguagem e a produção de representações resulta na formação de ordens de discurso, uma estrutura social discursiva.

${ }^{17}$ FAIRCLOUGH, Norman. Análise Crítica do Discurso como método em pesquisa social científica. 2 ed. Londres, 2005. 
Uma ordem discursiva em uma sociedade pode ser hegemônica, dominante, já estabelecida como senso comum ou alternativa, que se opõe à que domina ou foge do padrão.

Para o desenvolvimento da análise, a metodologia utilizada será composta pela adequação e aplicação das teorias referentes à Análise de Discurso Crítica (ADC). O direcionamento será com base nos estudos de Norman Fairclough. Com o entendimento de que a ADC é uma atividade multidisciplinar (FAIRCLOUGH, 2001), será utilizada também teorias do campo da Linguística para executar a análise textual dos discursos contidos no corpus. Essa análise corresponde à observação das diferentes estratégias e aspectos textuais utilizados na produção discursiva, com foco na categoria vocabulário. Sobre essa a análise do texto, Fairclough considera que

pode ser organizada em quatro itens: 'vocabulário', 'gramática', 'coesão', e 'estrutura textual'. Esses itens podem ser imaginados em escala ascendente: o vocabulário trata principalmente das palavras individuais, a gramática das palavras combinadas em orações e frases, a coesão trata da ligação entre orações e frases e a estrutura textual trata das propriedades organizacionais de larga escala dos textos (FAIRCLOUGH, 2001, p. 103).

Após a análise textual, segue-se para a análise das práticas discursivas. Desta, deriva a observação dos processos de produção, consumo e distribuição do texto. Sobre a produção, observam-se as rotinas e condições de produção de determinado discurso. Sobre consumo, observam-se as condições que possibilitam o leitor de ter contato com o texto e sua leitura. Referente à distribuição, busca-se observar os modos pelos quais aquele discurso foi distribuído em determinado ambiente, entre outros.

$\mathrm{O}$ aspecto argumentativo do gênero textual do artigo de opinião propõe um ambiente de disputa. Ao produzir um discurso persuasivo, de modo a convencer o leitor sobre determinado tema, o articulista se utiliza de uma forma de poder para exercer influência sobre o leitor. E é por conta desse ambiente de luta que se torna possível realizar a análise das práticas sociais, com foco nas estruturas da sociedade. Para isso, são utilizados os conceitos de ideologia e hegemonia.

Neste ponto, Fairclough (2001) passa a discutir os conceitos de ideologia e hegemonia, baseado em Althusser e Gramsci, "que oferecem uma teoria rica para a investigação do discurso como forma de prática social" (p. 116). Já do conceito de ideologia, entende-se como "significações/construções da realidade (o mundo físico, as relações sociais, as identidades sociais) que são construídas em várias dimensões das formas/sentidos das práticas discursivas" (FAIRCLOUGH, 2001, p. 117).

É possível perceber que a produção de discurso em artigos de opinião, com forte presença de argumentação e o conceito de ideologia estão muito próximos. E isso se 
intensifica ao se considerar o poder de constituir significações, conceitos e relações através da utilização de discursos permeados de argumentação que visam a, exatamente, tais processos de desconstrução de ideias antigas e construção de novas noções. Após estas considerações, passamos para a análise.

\section{OPINIÃO: SEIS ANOS DE OCUPAÇÃO - UMA ANÁLISE}

O artigo em destaque, "Opinião: Seis anos de ocupação", foi publicado no portal do Voz das Comunidades no dia 12 de dezembro de 2016. O texto foi escolhido para análise por retratar um tema relevante, uma análise da segurança pública da comunidade após seis anos da ocupação da PM-RJ no Complexo do Alemão, que teve início no ano de 2010, fato este que proporcionou maior destaque para o Voz, com a cobertura divulgada nacionalmente.

Quanto à análise textual, segundo o vocabulário utilizado, percebemos o lugar de fala do autor do texto, Betinho Casas Novas, na posição de morador do Complexo do Alemão, ao retratar os fatos repetidas vezes utilizando o termo "moradores", claramente destacando o ponto de vista dos moradores diante dos fatos retratados. Um dos trechos em que Betinho utiliza esta expressão corresponde à percepção dos moradores em relação à violência ainda persistente no local, mesmo com a presenta dos policiais militares: "Em 2014, logo no início do ano, os moradores já começavam a sentir o peso da violência que vinha desde a ocupação".

Durante o texto, a palavra "moradores” foi utilizada por quinze vezes. Dessa forma, toda a argumentação do artigo é realizada com base nas percepções dos próprios moradores, sem qualquer interferência de órgãos do governo, empresas, conglomerados midiáticos ou outra corporação que pudesse influenciar no conteúdo produzido sobre a presenta da PM na comunidade. Não há aqui o interesse em favorecer qualquer grupo por questões políticas ou econômicas. Também é importante destacar que tal fato não torna o texto como uma bandeira dos moradores contra o governo, os traficantes ou contra a polícia, já que Betinho retrata os malefícios que a própria PM sofreu, com a morte de policiais durante o período analisado no artigo, por exemplo.

Outro aspecto característico do texto em análise é a proximidade que o autor tem da rotina da comunidade e, obviamente, por estar inserido nesta, o que influencia diretamente o conteúdo produzido, diferentemente se o artigo tivesse sido escrito do lugar de fala de quem mora em um bairro nobre da cidade, por exemplo.

O autor retrata a violência como um problema ainda existente na comunidade, mesmo após a chegada da PM. Segundo Betinho, a violência continua "perseguindo a rotina 
dos moradores", e ainda "mantêm-se as placas de "Vende-se" ou "Aluga-se", penduradas nas casas, bares e comércios, pela favela"; tais trechos demonstram que o autor tem conhecimento do que acontece no local, demonstram sua proximidade com o mesmo.

Em alguns momentos, Betinho escreve o texto em terceira pessoa do singular, em outras, aparece a terceira pessoa do plural, no momento em que se inclui como morador, como no trecho "Já estávamos em 2016 (...)", por exemplo. Neste ponto, percebemos que o autor une sua voz e suas percepções aos dos moradores, como se ambos defendessem um mesmo ideal e uma mesma opinião dos fatos analisados.

Em relação aos personagens que aparecem representados no texto, além de Betinho - o autor, e dos moradores, citados em um agrupamento só, ainda são ouvidos os amigos da PM Fabiana Aparecida, que foi assassinada no Complexo após a ocupação. Em nenhum momento há no texto a utilização de fontes oficiais ou a fala que exponha posicionamento de órgãos oficiais, como a própria PM, da Secretaria de Segurança, do governo do Estado ou da prefeitura.

Quanto à análise das práticas discursivas, ela se orienta dividida em três partes: processo de produção, distribuição e consumo do texto.

Quanto à produção, é possível perceber que o artigo analisado foi produzido individualmente por Betinho Casas Novas, o que demonstra que ele mesmo dominou todos os processos, desde a coleta de informações à produção textual. Neste ponto, é fundamental a compreensão e a significação que o autor tem sobre a produção, ainda mais em se tratar de um artigo de opinião.

Segundo Bräkling ${ }^{18}(2000)$, o artigo de opinião é definido como um gênero discursivo utilizado para convencer o leitor e causar influência sobre determinado assunto, através de um "processo de argumentação a favor de uma determinada posição assumida pelo produtor e de refutação de possíveis opiniões divergentes” (BRÄKLING, 2000, p. 226). Desse modo, temos o produtor no texto como peça-chave para o conteúdo do texto. No artigo em questão, o autor é o repórter fotográfico Betinho Casas Novas, de 27 anos. Na página da web onde é possível acessar o texto, há uma breve descrição de Betinho como "nascido e criado no Alemão", "faz oficinas fotográficas para algumas crianças na comunidade do alemão para driblar a violência em seu bairro" e "tem como base a

18 BRÄKLING, Kátia Lomba. Trabalhando com artigo de opinião: re-visitando o eu no exercício da (re)significação da palavra do outro. In: ROJO, Roxane (Org.). A prática da linguagem em sala de aula: praticando os PCN. São Paulo: EDUC; Campinas, SP: Mercado de Letras, 2000, p. 221-247. 
comunicação comunitária participativa, sempre na imparcialidade, eternizando momentos do dia-a-dia, conflitos e prazeres da comunidade".

Apesar de ser caracterizado como fotógrafo, é perceptível que Betinho reconhece a ferramenta da publicação de textos no Voz das Comunidades como significativa para a constituição de opiniões diferentes das que são construídas pelos meios tradicionais sobre o Complexo do Alemão e as questões sociais que a perpassam. E isso está impresso não apenas no texto que o descreve, mas no texto que é por ele produzido.

A ausência de uma formação acadêmica voltada para a atividade jornalística pode influenciar na produção textual, mas este aspecto não é decisivo quanto à participação no Voz, já que é um meio de comunicação reconhecidamente colaborativo e comunitário, prezando por outros aspectos, como estar inserido no contexto da comunidade.

Outro item da análise das práticas discursivas corresponde ao consumo do texto. $\mathrm{O}$ artigo em questão pode ser consumido individualmente ou não. $\mathrm{O}$ acesso ao texto é restringido pelo acesso à internet. Como afirma Fairclough (2001),

Os processos de produção e interpretação são socialmente restringidos num sentido duplo. Primeiro, pelos recursos disponíveis dos membros, (...). Segundo, pela natureza específica da prática social da qual fazem parte (FAIRCLOUGH, 2001, p. 109).

Contribuem para o entendimento do texto quem conhece o cotidiano das comunidades do Rio de Janeiro ou, em específico, do Complexo do Alemão e a questão social da ocupação dessas comunidades pela Polícia Militar. Caso o leitor não compreenda bem esse contexto, o entendimento será insuficiente. Neste ponto, destacamos que o texto poderá ser melhor compreendido pelos moradores do Complexo do Alemão, que estão inseridos no contexto retratado no artigo, e também pelos Policiais Militares, também retratados como vítimas da violência, mesmo havendo pontos de conflito em que a PM é vista como responsável pelos atos de violência. Citamos aqui a explanação de Fairclough (2001) sobre a coerência de um texto:

Um texto só faz sentido para alguém que nele vê sentido. (...) os textos estabelecem posições para os sujeitos intérpretes que são 'capazes' de compreendê-los e 'capazes' de fazer as conexões e as inferências, de acordo com os princípios interpretativos relevantes, necessários para gerar leituras coerentes. Tais conexões e inferências podem apoiar-se em pressupostos de tipo ideológico (FAIRCLOUGH, 2001, p. 113).

Dessa forma, se um indivíduo que mora em outro país que não seja o Brasil e que não esteja ciente das situações de violência que costumam acontecer nas comunidades do Rio de Janeiro tiver acesso ao texto, dificilmente conseguirá compreendê-lo, ao menos que faça uma rápida pesquisa na internet sobre tal questão social. Um aspecto importante da 
análise do consumo, destacado por Fairclough (2001), corresponde aos efeitos que o texto pode causar ao ser lido. Segundo o autor,

Os textos apresentam resultados variáveis de natureza extradiscursiva, como também discursiva. Alguns textos conduzem a guerras ou à destruição de armas nucleares; outros levam as pessoas a perder o emprego ou a obtê-lo; outros ainda modificam atitudes, as crenças ou as práticas das pessoas (FAIRCLOUGH, 2001, p. 108).

Com base nesse entendimento e no contexto em que o Voz foi criado, percebemos que o artigo em análise busca por causar nos leitores mudanças quanto à compreensão do fato social da ocupação da PM no Complexo. Mas, quanto ao texto alcançar o objetivo desejado, é uma conclusão que não pode ser retratada nesta pesquisa, por conta das reações imprevisíveis que tal texto pode causar, a depender de quem o consome.

Quanto à distribuição, o texto possui distribuição complexa (FAIRCLOUGH, 2001), tanto pelos exemplares impressos quanto pela publicação na internet; não se restringindo à conversas casuais de distribuição simples. Assim, a distribuição ocorre em diferentes domínios, cada um deles com suas próprias rotinas de consumo.

No último ponto da análise, passamos a observar o discurso como prática social, observando dois itens: ideologia e hegemonia.

Quanto à ideologia, a compreendemos de acordo com a conceituação de Fairclough (2001), que a considera como "significações/construções da realidade (o mundo físico, as relações sociais, as identidades sociais) que são construídas e que contribuem para a produção, a reprodução ou a transformação das relações de dominação" (p. 117). Assim, consideramos que as ideologias inseridas no discurso de Betinho Casas Novas no artigo "Opinião: Seis anos de ocupação" correspondem às suas construções pessoais da realidade, segundo o fato de ser morador do Complexo do Alemão e participante de um meio de comunicação alternativo, envolvido ativamente nas questões sociais da comunidade, em busca de mudanças e melhorias.

Sobre ideologia, Fairclough (2001) também considera que esta está localizada "tanto nas estruturas que constituem o resultado de eventos passados como nas condições para os eventos atuais e nos próprios eventos quando reproduzem e transformam as estruturas" (p. 121). Aqui, consideramos que as ideologias de Bentinho se constituem como as que objetivo a proporcionar transformação de estruturas sociais, tanto quanto dos contextos de desigualdade.

Quanto a Hegemonia, Fairclough (2001) considera que é a "liderança tanto quanto dominação dos domínios econômico, político, cultural e ideológico de uma sociedade” (p. 122). Quanto a esse aspecto, consideramos que a produção textual de Bentinho se constitui 
como contra hegemônica. Primeiramente, por não se constituir como liderança em nenhum dos aspectos citados, e, em segundo lugar, por buscar ser uma opção diferente de produção midiática, destoante dos grandes meios de comunicação tradicionais e hegemônicos. Por fim, consideramos que o discurso de Bentinho busca a "transformação não apenas da ordem de discurso existente, (...) mas também das relações sociais e assimétricas existentes” (p.124).

\section{VOZ DAS COMUNIDADES: UMA SAÍDA DE EMERGÊNCIA}

Após a realização da análise discursiva crítica do artigo em destaque, "Opinião: Seis anos de ocupação", publicado no Voz das Comunidades em dezembro de 2016, é possível perceber que o discurso de Bentinho Casas Novas é permeado de marcas discursivas que demonstram sua proximidade com o a comunidade com o tema exposto. Sejam nas representações produzidas, sejam nas variadas vezes em que prioriza o ponto de vista dos moradores da comunidade, sem utilizar em nenhum momento fontes oficiais que interesses contrários aos dos moradores.

Compreendendo que tal posicionamento dificilmente seria publicado em um meio de comunicação tradicional, o qual costuma priorizar fontes oficiais como representantes de governos, de prefeituras ou outros órgãos e empresas. Assim sendo, o Voz das Comunidades se constitui como uma saída de emergência em uma sociedade pressionada a todo momento a adotar para si representações que rotineiramente vão contra o bem comum.

O fato de ser um meio de comunicação produzido em uma comunidade, que busca preservar a não-interferência de interesses particulares de terceiros, também é de grande importância para a manutenção de um discurso coerente com os anseios dos cidadãos aos quais intenta representar nas produções midiáticas.

\section{CONSIDERAÇÕES FINAIS}

Após a realização da presente pesquisa, concluímos que a existência do Voz das Comunidades, em seu contexto de resistência e oposição a meios de comunicação tradicionais imersos em interesses particulares - econômicos ou políticos, é fundamental para que haja um debate mais plural na sociedade, sobre diversos assuntos.

No contexto das comunidades, além de existir uma voz local, que tem a liberdade de retratar seus anseios e necessidades, é primordial a manutenção desta sem influências opostas. Assim, consideramos a internet e o uso de ferramentas como tecnologias móveis como grandes contribuintes para tal manutenção. 
Além do Voz das Comunidades, em ação no Complexo do Alemão, na cidade do Rio de Janeiro, consideramos ainda fundamental a existência de outros jornais comunitários por todo o país, para o bom funcionamento da sociedade e da democracia.

\section{REFERÊNCIAS}

BARBOSA, Suzana; SEIXAS, Lia. Jornalismo e Tecnologias Móveis. In: BARBOSA, Suzana. MIELNICZUK, Luciana (Orgs.). Jornalismo e tecnologias móveis, 2013. Labcom. p. 51 - 74.

BRÄKLING, Kátia Lomba. Trabalhando com artigo de opinião: re-visitando o eu no exercício da (re)significação da palavra do outro. In: ROJO, Roxane (Org.). A prática da linguagem em sala de aula: praticando os PCN. São Paulo: EDUC; Campinas, SP: Mercado de Letras, 2000, p. 221-247.

El País. A voz da comunidade que corre o Rio. El País, 2015. Disponível em: <brasil.elpais.com/brasil/2015/04/05/politica/1428194084_073598.html>. Acesso em: 23 de abril de 2019.

EVANGELISTA, Ana Paula Souto. Meios de Comunicação Tradicionais X Mídias Alternativas, Como Está a Qualidade da Informação que Chega á População? Disponível em: $<$ http://www.intercom.org.br/papers/nacionais/2008/resumos/r3-1448-1.pdf >. Acesso em: 22 de abril de 2019.

FAIRCLOUGH, N. Discurso e mudança social. Brasília: Editora Universidade de Brasília, 2001.

Londres, 2005.

Análise Crítica do Discurso como método em pesquisa social científica. 2 ed.

O VIGILLANTE. As fases do jornalismo. Disponível em: $<$ https://ovigillante.wordpress.com/2010/09/08/as-fases-do-jornalismo-resumo/>. Acesso em: 23 de novembro de 2018.

PRETTO; MARZULO. O conceito de favela/slum pelo IBGE e pela ONU. Disponível em: $<$ https://www.lume.ufrgs.br/bitstream/handle/10183/92016/Poster 30704.pdf?sequence $=2>$.

Acesso em: 26 de outubro de 2017.)

RESENDE, Viviane; RAMALHO, Viviane. Análise de Discurso (para a) Crítica: O texto como Material de Pesquisa. Campinas: Pontes, 2011. v. 1.

SILVA, Firmino Fernando. Repórteres em campo com tecnologias móveis conectadas. In: BARBOSA, Suzana; MIELNICZUK, Luciana. Jornalismo e Tecnologias Móveis. Covilhã: Labcom, 2009. p. 91-112.

TELE SÍNTESE. $\mathbf{6 1 \%}$ dos brasileiros têm acesso à Internet. Disponível em: <http://www.telesintese.com.br/tic-domicilios-2016/>. Acesso em: 29 de julho de 2019.

VAN DIJK, T. Racism in the press. London: Arnold, 1986.

VAN LEEUWEN, T. IN: Análise Crítica do Discurso. [S.l.] Editorial Caminho, 1998. p. 169-222.

VOZ DAS COMUNIDADES. Ficha técnica. Disponível em: $<$ http://www.vozdascomunidades.com.br/ficha-tecnica/>. Acesso em: 26 de otubro de 2017. 
Nossa história. Disponível em: $<$ http://www.vozdascomunidades.com.br/geral/nossahistoria/>. Acesso em: 26 de outubro de 2017.

Seis anos de ocupação. Disponível em: $\overline{<\mathrm{https} \text { ://www.vozdascomunidades.com.br/comunidades/complexo-do-alemao/opiniao-seis- }}$ anos-de-ocupacao/>. Acesso em: 29 de julho de 2019.

ZAGO, Gabriela da Silva. Recirculação jornalística no twitter: filtro e comentário de notícias por interagentes como uma forma de potencialização da circulação. 2011. $204 \mathrm{f}$. Dissertação - Universidade Federal do Rio Grande do Sul, Porto Alegre - RS. 